\title{
Vicher: A Virtual Reality Based Educational Module for Chemical Reaction Engineering
}

\author{
JOHN T. BELL and H. SCOTT FOGLER
}

Department of Chemical Engineering, University of Michigan, $2300 \mathrm{Hayward,} 3074 \mathrm{Herbert} \mathrm{H.} \mathrm{Dow} \mathrm{Building,}$ Ann Arbor, Michigan 48109-2136

\begin{abstract}
Virtual reality has the potential to be a powerful new tool in engineering education by bringing experience-based learning to all students, addressing the needs of students with alternate learning styles, and providing enhanced impact to educational presentations. As with any new tool, we must first learn how, when, and where to apply it before it becomes useful. This article describes Vicher, the first known application of virtual reality to chemical engineering education, and some of what has been discovered about virtual reality as an educational tool during Vicher's development. Vicher currently consists of two programsVicher I and Vicher II - which deal with the topics of catalyst deactivation and nonisothermal effects in chemical reaction engineering, respectively. Between the two programs, Vicher currently simulates five different engineering areas plus support facilities. Future plans include extensive student testing, program expansion and refinement, and the development of additional virtual reality based educational modules. (C) 1996 John Wiley \& Sons, Inc.
\end{abstract}

\section{INTRODUCTION}

This article describes the first foray into a totally new area of computer-assisted engineering education, virtual reality (VR). Although VR has been under development since the mid-1960s [1], it has taken recent technological breakthroughs [2-8] to make this tool accessible to a wider audience, including engineering educators. Even with the rapid improvements in price/performance ratios of VR technology, however, chemical engineers and engineering educators have not yet taken advantage of this new technology. The reasons for that lack of use are the same as with any new technological

Computer Applications in Engineering Education, Vol. 4(4) 285-296 (1996)

(c) 1996 John Wiley \& Sons, Inc.

CCC 1061-3773/96/040285-12 development: The benefits to be gained from VR, its capabilities, its applicability to engineering tasks, and its optimal implementation procedures are not yet fully understood. (Just as personal computers were considered toys before the development of spreadsheet and word-processing applications turned them into vital business tools.) To explore and illustrate some of the capabilities of VR and its applicability to engineering and education, a prototype VR-based educational module, Vicher, has been developed in the chemical engineering department of the University of Michigan in Ann Arbor. This article focuses primarily on the presentation of Vicher itself and also discusses some of what has been learned during the development and testing of Vicher. Additional findings concerning the effective application of VR to scientific and technical education that have resulted from the development of 
Vicher and other programs will be presented in a later paper.

\section{VIRTUAL REALITY}

Virtual reality is an emerging computer interface technology that attempts to pull users inside computer simulations, convincing them that they are actually within the computer-generated world, as opposed to viewing the simulation from a passive external viewpoint. The ultimate ideal of VR is the creation of computer simulation environments that are so realistic as to be completely indistinguishable from the real world [4-7].

The two most widely known pieces of equipment used to approach that ideal are head-mounted displays (HMDs) [9] and wired gloves [10]. The HMD is a display device worn on the head that often provides stereoscopic vision and usually incorporates a head tracker to monitor the position and orientation of the user's head. The HMD immerses the user deeply within the simulation by blocking out all views of the real world, freeing the user from the stationary computer screen, and providing interactive feedback that adjusts the display to match the user's viewpoint. A major contributor to the HMD's impact arises from sensory deprivation - when users cannot see the real world, they become much more immersed in the virtual one. The wired glove provides information to the simulation concerning the position, orientation, and configuration of the user's hand and digits. This information is generally used to provide feedback through the manipulation of a simulated hand within the virtual world, although alternate uses of wiredglove information have also been employed. Realistic sound cues are important in VR, and researchers are also developing haptic feedback, olfactory stimulus, and other interface technologies. Techniques from psychology, theater, and legerdemain are also used to enhance the believability of virtual simulations.

\section{EDUCATIONAL BENEFITS OFFERED BY VR}

\section{Experiential Learning}

Experience is a powerful learning tool, and the one that provides the best long-term retention rate [11]. Students who hear a lecture on chemical production will retain some of the information presented; those who view a film will retain more. But for those allowed to visit a working facility, see the equipment, hear the noises, and smell the smells - that is the group that will retain the most information for the longest time and with the greatest clarity. There are many reasons, however, why it is not practical to expose large numbers of students to operational chemical plant conditions, including safety, economic, and logistic constraints. VR, on the other hand, has the potential to provide all students nationwide with unlimited access to chemical manufacturing facilities, without endangering themselves or anyone else, at minimal cost, at their convenience, and without disrupting plant operations. VR can bring experience to the masses.

\section{Alternate Learning Styles}

Students learn through many different mechanisms, including lectures, books, demonstrations, and experimentation. The relative effectiveness of these mechanisms varies from student to student, reflecting differences in their learning styles [12-16]. These learning styles have many dimensions, including verbal versus visual, sequential versus global, and passive versus active. Verbal learners are those who learn well from word-based interfaces such as books and lectures, whereas visual learners are more attuned to visually oriented stimuli such as pictures, graphs, and movies. On another scale, passive learners absorb material well in a passive learning environment (e.g., most lectures), while active learners excel through participatory activities such as laboratories and workshops. Sequential learners are able to grasp new material in discrete steps, reaping partial understanding from incomplete instruction, whereas global learners must understand all facets of a topic before the details have meaning.

Learning styles have been studied extensively by many researchers [12-16], including Felder and Silverman [12], who determined that traditional educational methods (which are primarily verbal, passive, and sequential) match the optimal learning styles of only a small portion of the typical undergraduate engineering student population. The majority of these students are then left with teaching methods that do not match their optimal mode of learning. VR has many features that make it ideal for meeting the needs of those students whose learning styles are not well served by traditional teaching methods. VR is a highly visual environment that strongly appeals to visual learners, and yet the use of a narrative track allows it to address the needs of verbal learners simultaneously. Active learners will benefit from the highly interactive experience 
afforded by VR, and global learners will gain a better understanding of how individual concepts and details intermesh.

\section{Repetitive, High-Impact Information Delivery}

Dale [17] reported previously that students retain $10 \%$ of what is read, $20 \%$ of what is heard, $50 \%$ of what is both heard and seen, and up to $90 \%$ of what is both spoken and acted upon. The more times that the same information is delivered through different channels and the more active the learning process, the better the concepts are understood and the longer the material is retained in memory. The beneficial value of repetition makes virtual reality attractive to educators on two fronts: (1) VR is not intended to replace traditional methods of education, but rather to augment them with another delivery mechanism; and (2) VR incorporates inherent repetition via the simultaneous presentation of the same information through multiple channels. VR is also a highly sensuous experience, surrounding the user with sight, sound, color, motion, tactile feedback, and possibly soon smell and taste. These senses can be orchestrated by the virtual world designer in a synergistic fashion to create an experience that has great impact.

\section{Unconstrained Exploration}

Educational experiences are rarely provided without some constraints, even for those who are able to visit or work in a chemical production facility. Industrial trainees, for example, are often presented with complex, expensive, and hazardous equipment and instructed to learn its proper operation without causing any process disruptions or hazardous conditions. Students in laboratory courses are expected to use glassware and fragile equipment without breaking anything or spilling chemicals. Situations such as these can lead to hesitancy caused by fear of damaging the equipment or causing an accident. VR provides the opportunity to explore and experiment in a completely unconstrained manner. A student wishing to observe reactor conditions first-hand is free to step inside and look. (It is then the responsibility of the virtual world designer to model the reactor interior accurately and to include appropriate educational information.) Students can operate virtual equipment at whatever conditions they desire, and if an explosion results, the only casualties will be virtual. In a process design environment, VR can provide students with the creative control to combine materials, equipment, and concepts in whatever combinations they choose to explore.

\section{VICHER: VIRTUAL CHEMICAL REACTION MODULE(S)}

\section{General Information}

Vicher (Virtual Chemical Reaction Module) is a VR application for undergraduate chemical kinetics and reactor design education. Vicher was originally developed as a simulation of a (portion of a) modern chemical plant consisting of a welcome center, two reactor rooms, two microscopic areas, and a debriefing center. As Vicher expanded, it was split into two separate entities, currently named Vicher I and Vicher II. The following sections first cover areas common to both programs (including some discarded from the original Vicher) and then those specific to Vicher I and Vicher II. The engineering concepts portrayed in Vicher are based upon Fogler [18] and are also covered in other texts [19-22].

\section{Required and Optional Hardware}

For an educational tool to be effective, it must be readily accessible to students. Vicher has therefore been developed on ordinary personal computers, instead of the graphics supercomputers more commonly used for VR. The exact hardware chosen, 90$\mathrm{MHz}$ Pentium-based PCs, was the fastest available when this project began, but has since dropped in price as more powerful PCs have been introduced. No special equipment is required to run Vicher, and the program has been successfully tested (albeit slowly) on platforms as low as a $40-\mathrm{MHz} 386$ (with coprocessor). Vicher does require a video card capable of 32 or $64 \mathrm{~K}$ ( 15 or 16 bit) colors and a joystick, although the latter requirement will be removed soon. It is not appropriate to run Vicher from a network server, because of speed requirements.

Several optional devices have been tested with Vicher, with the expectation that they would become affordable to students within the next few years. As a confirmation of that expectation, the first head-mounted display/head tracker combination purchased for this project cost nearly $\$ 3000$ in mid-1994 [23,24], whereas a newly developed device with similar capabilities was acquired in late 1995 for only $\$ 800$ [25]. Other optional devices supported by Vicher include stereoscopic LCD shutter glasses [26], Simsalabim 3-D viewing Cyberscope [27], and Crystal River Engineering's 3-D stereo sound card [28]. Six-degree-of-freedom 


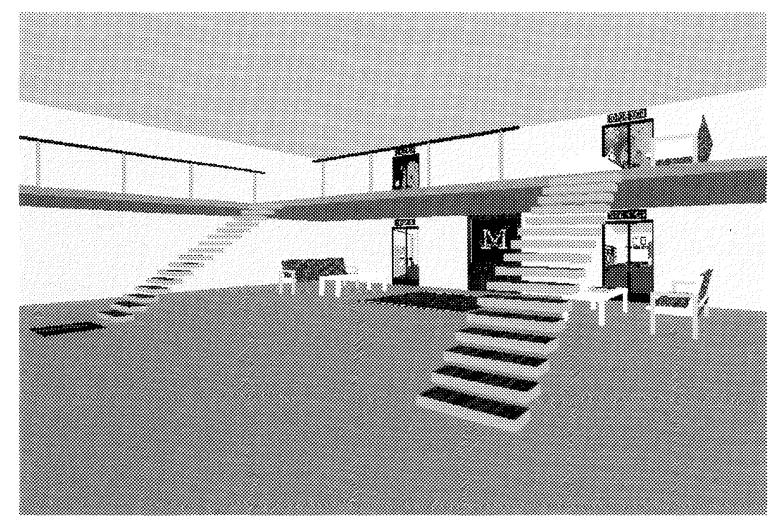

Figure 1 The Vicher 1 welcome center contains escalators leading to the upper balcony.

mice [24] have been evaluated but not implemented.

\section{Software and Operating Systems}

To serve as wide a potential audience as possible and for future growth, Vicher is being developed using the WorldToolKit (WTK) development package from Sense8 corporation [29]. The advantage of WTK is the range of platforms supported, including Microsoft Windows 3.1, DOS, HP, Sun, DEC Alpha, Silicon Graphics, and more recently, Windows NT. (Support for the Macintosh operating system is rumored within the next year.) Vicher currently has versions for Windows 3.1 and DOS, the latter of which unfortunately requires a graphics board that is no longer manufactured. The Windows version of Vicher has been successfully run under Windows 95, but has not been tested under Windows NT. Other software employed in the development of Vicher includes Borland $\mathrm{C} / \mathrm{C}++$, Watcom HighC, AutoCAD r12, Pharlap DOS extender, Adobe PhotoStyler, MKS Toolkit, Ofoto, and CorelDraw 5.

\section{User Interface}

Users interface with Vicher using a joystick for movement, a mouse for activating objects and requesting information, and a keyboard for other tasks. The left mouse button is used to "activate" objects such as television or reactor controls, where "activate" takes on a meaning appropriate to the object. Pictures can be activated to teleport to the location shown. Alternatively, users can fly through pictures or doorways, which also act as teleports. Clicking the right mouse button opens a new window containing object-specific help (MS Windows version only). Additional help can then be obtained via a standard hypertext help interface. The joystick is particularly effective when used with a head tracker, as the user may simply look at a desired destination and push the stick forward to move in that direction.

\section{Getting Started}

The original Vicher began with a welcome center, the purposes of which were twofold. The first was to overcome disorientation problems that some users experience when first encountering VR. The welcome center was designed as a simple, familiar environment in which users could become comfortable with VR before continuing on to more complex and possibly abstract environments. This room has been quite effective in this role and therefore welcome centers have been included in both Vicher I and Vicher II, as shown in Figures 1 and 2, respectively. The second role of the welcome center was an information center providing educational information from pictures, books, bulletin boards, and a virtual television set, the latter of which also introduces users to virtual controls. Current versions of Vicher have television sets in every room to provide roomspecific information as appropriate.

The welcome center also provides a central base of operations from which to explore other areas, most of which have direct access to and from the welcome center. Early versions of Vicher contained hallways leading from the welcome center to other areas, designed to provide a logical transition between rooms. However, the hallways turned out to be difficult for users to traverse and added little to the overall experience. When teleports became available, users generally chose to use the teleports rather than the hallways, with no resulting disorien-

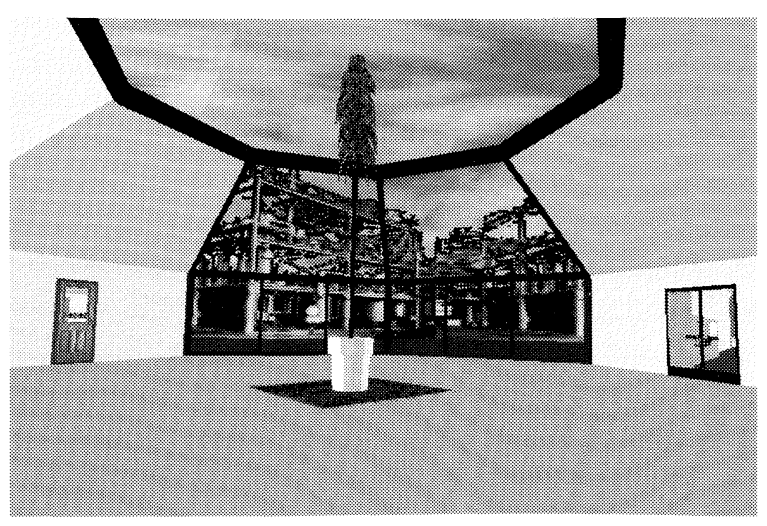

Figure 2 The Vicher 2 welcome center revealed problems with symmetrical rooms. 
tation. Therefore, all hallways have since been removed in favor of teleports as the preferred transfer mechanism. This change has provided increased flexibility for adding and removing rooms and for adjusting interconnectivity between areas.

One problem with the original welcome center that was discovered when designing the Vicher I and Vicher II welcome centers involves disorientation caused by excessive symmetry. The original Vicher welcome center was a simple rectangular room with doors and windows placed evenly about the perimeter. The Vicher I welcome center is a two-story room with an L-shaped balcony reached by escalators (Fig. 1), and the Vicher II welcome center is an octagonal room with a high ceiling tapering to a small central skylight (Fig. 2). The orientation problem, which is most pronounced in Vicher II, is caused by the lack of directional cues in a symmetric room. Without these cues, users easily become disoriented, particularly if they have teleported into the room. The original welcome center has fewer problems than the octagonal room of Vicher II, but it still suffers from too much symmetry. Vicher I has the best configuration, as the balcony and escalators provide an instantly recognizable sense of direction. The symmetry of the Vicher II welcome center has been reduced by adding furniture and replacing some solid walls with floor-toceiling windows, but additional direction-indicating mechanisms are still needed.

\section{Interactive Interrogation}

Early versions of Vicher were modeled roughly after other interactive educational computer modules [30], in which users are presented with information, given an opportunity to experiment, and then asked a series of questions that must be answered correctly to receive a good "grade" for the module. With this framework in mind, Vicher originally contained a debriefing center in which to question students before they exited the simulation. The purposes of this room were threefold: to test students' mastery of the concepts covered in the simulation, to produce a "grade" for running the simulation, and to inspire students to go back and further explore issues that were not fully grasped initially.

The problem that arises is the determination of an effective method of querying users in a virtual environment and the subsequent recognition and recording of their response. This issue has not been addressed by other VR developers, who are primarily interested in creating more realistic environments, or by traditional educational software developers, who are not faced with the constraints im- posed by VR. The traditional method of questioning a computer user - printing a question to the screen and requesting that the user type in a responseis not generally applicable to virtual environments because there is not always a text screen present and the user does not always have access to the keyboard. The VR screen is graphic and can be viewed from an infinite variety of viewpoints. Headmounted displays compound the problem by providing low-resolution visual acuity and by blocking visual access to the keyboard and other materials. In the particular case of Vicher, the difficulties are further compounded by the desire to support as many hardware platforms as possible.

Several methods have been investigated for presenting textual information in a virtual world without yielding consistently satisfactory solutions. The most promising techniques are the separate window and the virtual television, the latter of which can record users' responses to multiple-choice questions. The drawback to the separate window is that the text cannot be read in currently available headmounted displays, and the drawback to the television is that only very short phrases can be clearly displayed. The televisions in Vicher currently serve only as information delivery mechanisms. Investigations continue into text presentation and questioning methods for use in virtual environments. As for the debriefing center, lack of a suitable questioning mechanism has eliminated the usefulness of this room, and so it has been removed from current versions of Vicher.

\section{VICHER I: CATALYST DEACTIVATION}

Vicher I illustrates concepts of catalyst deactivation in industrial practice and common industrial responses to decaying catalyst. When completed, there will be three reactor rooms present in this simulation corresponding to slow, medium, and rapid catalyst decay, plus microscopic exploration areas that allow students to observe catalytic reaction mechanisms on a molecular scale. The straightthrough transport reactor room and the microscopic areas were carried over and enhanced from the original Vicher program. The moving-bed reactor room for the study of medium decay is under construction.

\section{Time-Temperature Room: Slow Catalyst Deactivation}

Catalysts whose activities decay slowly over time lead to gradually declining reactor performance and inconsistent product quality. The effects of slowly 


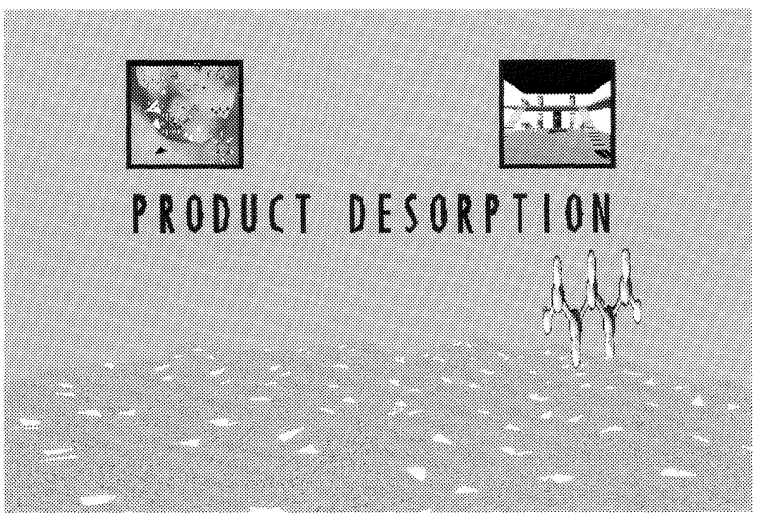

Figure 7 A close up view of the catalyst surface (within the pore.)

provide teleport access back to other areas of the simulation.

The microscopic areas of Vicher I provide access to otherwise inaccessible environments and allow observation of events that are not directly observable without a simulation of some kind. The pore interior has a particularly high impact owing to its extremely immersive nature, which pulls students into the simulation and surrounds them with activity. The disadvantages are the orientation and navigation difficulties that many users encounter in this irregular, abstract, and unfamiliar environment. Visual learners benefit from the ability to watch reactions take place, and active learners will remember the experience of pursuing molecules to observe a reaction subject to kinetic probabilities.

\section{VICHER II: NONISOTHERMAL EFFECTS}

Vicher II focuses on nonisothermal effects in chemical kinetics and reactor design, including the formation of localized hot spots caused by exothermic reaction within a jacketed packed-bed reactor (PBR), the presence of multiple steady states in a continuous-stirred tank reactor (CSTR), and the use of sequential reactors with inter-stage heat transfer to overcome temperature dependent limitations. The nonisothermal PBR room is the only portion of the original Vicher program that has been incorporated into Vicher II. The staged reactor area is currently under development.

\section{Nonisothermal PBR Room}

The nonisothermal PBR room contains equipment and concepts for the study of the exothermic oxida- tion of sulfur dioxide, as shown in Figure 8 [18, Example 8-10]. Specific equipment consists of a jacketed PBR, represented as a double-pipe heat exchanger with tube-side catalyst packing and shellside baffles for the cooling fluid, and an associated control panel. The reactor can be made transparent for improved observation of internal conditions. A 3-D mathematical surface displays reaction kinetics as a function of temperature and fractional conversion.

Temperature information is conveyed through the extensive use of color, with high temperatures indicated by shades of red, low temperatures by shades of blue, and intermediate temperatures colored white. This color coding scheme is used both on the kinetics surface and within the reactor, providing a visible relationship between the abstract mathematics and the physical reality of the equipment. Internal conditions along the length of the reactor are indicated by a set of operating lines that lie on and just above the kinetics surface, with each line corresponding to a different set of reactor inlet conditions. These lines are coplanar with the kinetics surface at the reactor inlet and diverge from the surface at the reactor exit as a result of the pressure drop that is accounted for in the operating lines but not in the isobaric kinetics surface.

When the reactor inlet temperature is low, the cooling fluid maintains reactor operating conditions in a range at which only modest rates of reaction occur. At higher reactor inlet temperatures, a localized hot spot appears near the reactor entrance, caused by the inadequacy of the cooling fluid to completely control the exothermic reaction. As the inlet temperature is raised, students observe the hot spot increasing in intensity and shifting towards the reactor entrance. Careful analysis of the operating lines and the kinetics surface using material and concepts covered in class should reveal the signifi-

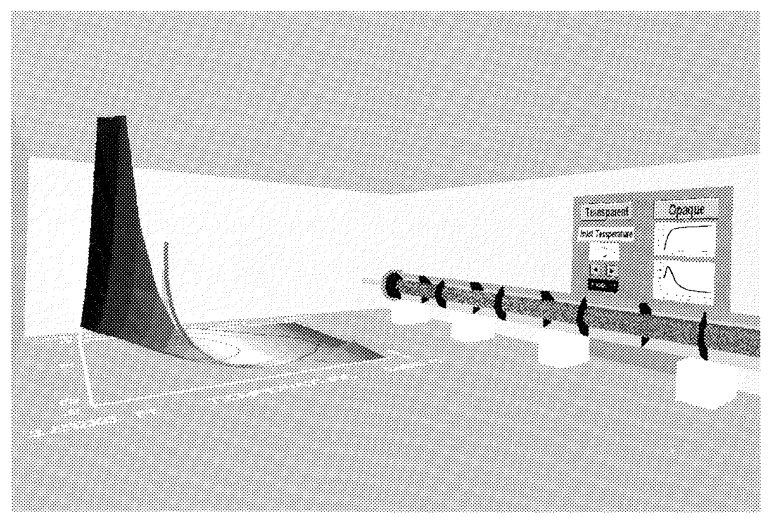

Figure 8 Nonisothermal packed bed reactor room, showing color coding on surface and in reactor. 
cance of these responses. Temperature and fractional conversion are also displayed as functions of reactor length via conventional 2-D graphs on the control panel.

The educational mechanisms being employed in the nonisothermal PBR room include the use of color as an information delivery mechanism, and the interconnectedness of the 3-D mathematical surface and the physical reality that it represents. The former appeals particularly to visual learners, and the latter helps global learners to see the significance of the mathematics and how it relates to an actual physical situation. All students benefit from the opportunity to freely explore the relationships between temperature, reaction rate, equilibrium, and reactor volume.

\section{Multiple Steady-States Room}

Exothermic reactions in jacketed CSTRs can lead to multiple steady-state conditions under which the. heat generated by the reaction is exactly balanced by the system cooling capacity. Failure to control these reactions properly can lead to sudden, unexpected, and dangerous shifts from one steady state to an alternate state at a significantly elevated temperature. Equipment available for studying this phenomenon in the multiple steady-states room includes a jacketed CSTR, which can be made transparent for internal observations, and an associated control panel, as shown in Figure 9. Reactor inlet and operating temperatures are indicated by digital readouts on the control panel and by color changes in the appropriate equipment. The control panel also provides for adjustments to the reactor inlet temperature as well as a graphic display of heat generation and removal and current steady-state conditions.

Operation of the reactor at varying inlet temperatures reveals the classic ignition-extinction response associated with this set of reactor conditions. As the inlet temperature is slowly raised, the reactor remains at a low-temperature steady state until the ignition point is reached, at which point reactor conditions shift abruptly to a high-temperature steady state. Lowering the inlet temperature does not result in a significant decrease in reactor operating temperature until the extinction point is reached, causing the operating temperature to drop sharply. The educational benefits afforded by this section of the simulation are similar to those present in other rooms: active participation, experience-based learning, visual information delivery, and an opportunity for global learners to relate mathematical concepts to physical situations.

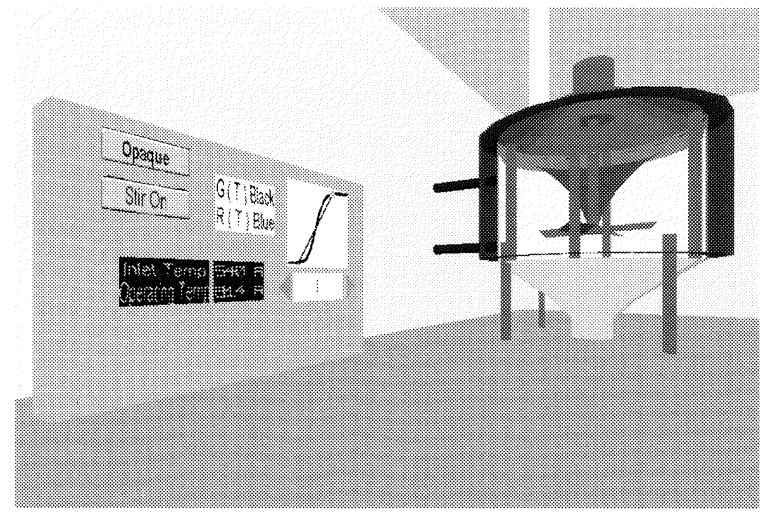

Figure 9 Multiple steady states are illustrated in this room.

\section{PRELIMINARY RESULTS}

The most apparent results of this work are the Vicher modules. Expertise has also been developed that will prove valuable in future educational and engineering applications. This expertise pertains not only to programming and graphical techniques, but also to computer-human interfaces and the effective application of VR to technical subjects.

Student testing has thus far been limited, but this situation is changing with the recent addition of several hundred Pentium PCs and two low-cost head-mounted display units to the University of Michigan's engineering computing facilities. Arrangements are also being made to beta-test the programs at other select universities. Many demonstrations of Vicher have been provided since the project's inception, involving hundreds of engineers, scientists, educators, and students of all grade levels. Much has been learned from observing participants during these demonstrations, and program modifications have been made accordingly. (Besides direct observation, Vicher also has provisions for videotape recording and for data base logging of user's actions.)

\section{STRENGTHS AND WEAKNESSES OF VR AS AN EDUCATIONAL TOOL}

Virtual reality is a new tool, and as with any new tool there are applications for which it is well suited and those for which it is not. To make the best use of this tool, it is necessary to understand its strengths, its weaknesses, and its unique implementation requirements. 


\section{Strengths}

Virtual reality offers many potential benefits to the engineering educator, including experiential learning, the ability to reach students with alternate learning styles (particularly visual and global learners), the use of multiple delivery systems for providing educational information, and the total immersion of the student within the educational experience. Headmounted displays provide added realism and immersion benefits. True stereoscopic 3-D vision is available at the cost of both money and performance. VR is an excellent tool for illustrating spatial relationships and exploring environments that are otherwise inaccessible. Students also show strong interest and enthusiasm for VR.

\section{Weaknesses}

These benefits do not come without their inherent drawbacks, however. Execution speed is of critical importance in VR, which necessitates certain compromises in simulation accuracy and detail to maintain reasonable system performance. Stereoscopic display reduces performance by roughly half. HMDs restrict access to the outside world, and the low resolution of student-affordable units significantly reduces effective visual acuity. VR is not an appropriate tool for displaying text, equations, or formulae at this time, although efforts are being made to overcome this limitation. The joystick is not familiar to all students and is not available for all computer platforms.

\section{Accounting for the Strengths and Weaknesses of VR}

The combination of high-speed requirements and low visual acuity results in unique simulation priorities, in which technical accuracy is sacrificed in favor of execution speed. (Users cannot discern errors below 10 or $20 \%$, but if calculation time exceeds a fraction of a second, the delay will be distinctly noticeable.) This situation requires many theatrical, psychological, and magician's tricks to produce effective qualitative experiences, rather than strict quantitative accuracy. Two extensively used techniques are to perform as many calculations as possible off-line, so that the virtual simulation only displays the results, and to use simple approximations for any calculations performed in real time. Specific details of some of the techniques employed in Vicher will be the subject of a separate paper.

\section{WORK IN PROGRESS}

Although the Vicher programs are approaching completion, there are still some areas under development and others in need of improvement. Two areas that are specifically under construction at the moment are the moving-bed reactor area in Vicher I and the staged reactor area in Vicher II.

The moving-bed reactor area will illustrate a typical industrial procedure for handling intermediate rates of catalyst decay. In this approach, catalyst slowly falls through a fluidized-bed reactor, taking hours, days, or even weeks to work its way through from top to bottom. The spent catalyst is removed from the bottom of the reactor, and either discarded or sent to a separate catalyst recovery facility. The mechanical design for the moving-bed reactor was taken from Walas [31, Fig. 17.28(c)].

The staged reactor area will illustrate the use of multiple reactors in series with interstage heat transfer. This approach is employed when the heat of reaction changes the reactor temperature such that the rate of reaction diminishes as the result of either kinetic or equilibrium causes. A mathematical representation of the equilibrium state as a function of temperature is also planned for this world, illustrating reactor operating conditions at various points along the reactor sequence.

The virtual televisions (present in every room) need more and better information, and the MS Windows "help" documentation needs to be expanded. Some areas require increased realism or educational effectiveness, or both. Methods are being investigated for the effective presentation of textual information and for questioning participants interactively. It is hoped that large-scale student testing at several engineering universities will yield a statistical measure of the educational effectiveness of Vicher. Written instructions are needed for students, instructors, and computer system administrators. Supplemental materials, such as questionnaires to test students' mastery of the concepts, will also be useful. It is hoped that widespread distribution of the Vicher modules (via the CACHE corporation [32]) can commence within the next year.

It has always been planned to port Vicher from the common PC to alternate platforms, such as Windows NT, Silicon Graphics, and HP workstations, to reach as wide an audience as possible. Now that Vicher is reaching maturity, this phase of the operation is commencing. Expected compatibility problems include the lack of joystick support under Windows NT and SGI platforms.

Other educational applications are being developed to explore different aspects of VR, including 
the portrayal of technical information, spatial relationships, and hazardous environments [33]. The most significant of these applications, involving a safety analysis of a polyether polyol pilot plant facility, was recently evaluated by 150 senior plant design students [34].

\section{CONCLUSIONS}

Virtual reality has tremendous potential to provide enhanced vision to students and engineers. Before that potential can be fully realized, however, it is necessary to identify which applications are best suited to VR, and how best to apply the technology to engineering topics. As a beginning exploration into this area, a series of VR-based educational modules are currently being developed in the Chemical Engineering Department of the University of Michigan. This article has described the Vicher. modules, which illustrate concepts of catalyst deactivation and nonisothermal effects in chemical reaction engineering. The other modules under development will investigate different applications of VR to engineering education. Preliminary testing of the Vicher programs shows a strong student response and an indication of increased understanding of the concepts covered. Additional testing with larger numbers of student participants is under way. The latest information regarding the activities of the Vicher project, including color versions of all figures used in this article, is available from http:// www.engin.umich.edu/labs/vrichel.

\section{ABOUT THE DEMO SOFTWARE}

The Vicher programs each require tens of megabytes of disk space, far beyond what is practical to include on a floppy disk. Therefore, the demo program that accompanies this article is restricted to the pore interior region of Vicher I only. Because the demo was created from the original Vicher, it does not include the staged areas described in the text. The accompanying help file describes the original Vicher as of the date the demo was produced. The demo has been run successfully on half a dozen different computer systems, but it has not been tested on all possible combinations of hardware and software. Additional documentation may be found on the included floppy disk.

\section{ACKNOWLEDGMENTS}

The authors gratefully acknowledge the undergraduate student programmers who have assisted in the development of the Vicher modules: specifically, Christian Davis, Darren Obrigkeit, Shawn Way, Jeroen Spitael, Paul Sonda, Anita Sujarit, Scott Whitney, Adam Deedler, and Pieter Spitael (in chronologic order). Thanks are also given to Dr. Joseph Louvar and Lawrence James of BASF Chemical Corporation, and to Tom Pakula of Marathon Oil Company for the valuable resources that they have provided, and to the University of Michigan Department of Chemical Engineering for initial funding.

\section{REFERENCES}

[1] I. E. Sutherland, “The ultimate display," Proceedings of the IFIP Congress, 1965.

[2] J. T. Bell and H. S. Fogler, "Low-cost virtual reality and its application to chemical engineering - part one,' CAST Communications, Vol. 18, No. 1, American Institute of Chemical Engineers, New York, 1995.

[3] J. T. Bell and H. S. Fogler, "Low-cost virtual reality and its application to chemical engineering - part two,' CAST Communications, Vol. 18, No. 2, American Institute of Chemical Engineers, New York, 1995.

[4] K. Pimentel and K. Teixeira, Virtual Reality: Through the New Looking Glass, 2nd ed., Windcrest Books, 1995.

[5] D. Stampe, B. Roehl, and J. Eagan, Virtual Reality Creations, The Waite Group, Corte Madera, CA, 1993.

[6] L. Jacobson, Garage Virtual Reality, Sams Publishing, Indianapolis, IN, 1994.

[7] L. C. Larijani, The Virtual Reality Primer, McGrawHill, New York, 1994.

[8] R. Hollands, "Technology review: Sourceless trackers,' VR News, Vol. 4, No. 3, April 1995.

[9] A. Zwern, "How to select the right HMD," $V R$ World, Vol. 3, No. 2, March/April 1995.

[10] H. Eglowstein, "Reach out and touch your data," BYTE, Vol. 15, No. 7, July 1990.

[11] D. A. Kolb, Experiential Learning: Experience as the Source of Learning and Development, PrenticeHall, Englewood Cliffs, NJ, 1984.

[12] R. M. Felder and L. K. Silverman, "Learning and teaching styles in engineering education," J. Eng. Educ., Vol. 78, No. 7, April 1988, pp. 674-681.

[13] C. G. Jung, Psychological Types, Princeton University Press, Princeton, NJ, 1971.

[14] G. Lawrence, People Types and Tiger Stripes: A Practical Guide to Learning Styles, 2nd ed., Center for Applications of Psychological Type, Gainesville, FL, 1982. 
[15] B. S. Soloman, Inventory of Learning Styles, North Carolina State University, Raleigh, NC, 1992.

[16] J. E. Stice, 'Using Kolb's learning cycle to improve student learning," J. Eng. Educ., Vol. 77, No. 5, February 1987.

[17] E. Dale, Audio-Visual Methods in Teaching, 3rd ed., Holt, Rinehart, and Winston, New York, 1969.

[18] H. S. Fogler, Elements of Chemical Reaction Engineering, 2nd ed., Prentice Hall, Englewood Cliffs, NJ, 1991.

[19] O. Levenspiel, Chemical Reaction Engineering, Wiley, New York, 1972.

[20] C. N. Satterfield, Heterogeneous Catalysis in Industrial Practice, 2nd ed., McGraw-Hill, New York, 1991.

[21] R. Hughes, Deactivation of Catalysts, Academic Press, Orlando, 1984.

[22] C. G. Hill, An Introduction to Chemical Engineering Kinetics and Reactor Design, Wiley, New York, 1977.

[23] General Reality Company, 124 Race St., San Jose, CA 95126.

[24] Logitech, Inc., P.O. Box 4293, Woodland Hills, CA 91365-9656.

[25] Virtual I. O., Inc., 1000 Lenora St., Suite 600, Seattle, WA 98121.

[26] StereoGraphics Corporation, 2171 East Francisco Blvd., San Rafael, CA 94901.

\section{BIOGRAPHY}

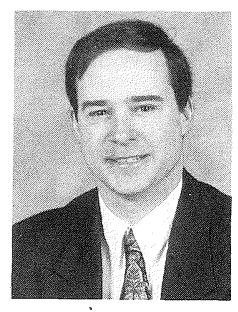

John T. Bell, lecturer, teaches chemical engineering at the University of Michigan. His current research work combines his $\mathrm{PhD}$ in chemical engineering (modeling and simulation) with his MS in computer science to study the applicability of virtual reality to chemical engineering and educational applications. Additional information can be found through http://www.engin.umich.edu/dept/ cheme/bell.html.

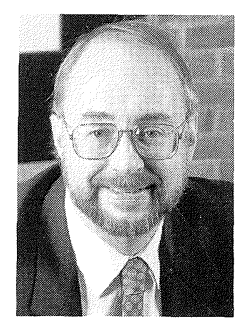

H. Scott Fogler, the Vennema Distinguished Professor of Chemical Engineering at The University of Michigan, has research interests in flow and reaction in porous media, colloid stability, wastewater treatment, and dissolution kinetics in microelectronics fabrication. He is author of over 130 research publications in these areas. In addition, he is author of four books. The Elements of Chemical Reaction Engineering, 2nd edition, published by Prentice Hall in 1992, is the most used book on this subject in
[27] Simsalabim, P.O. Box 4446, Berkeley, CA 947040446.

[28] Crystal River Engineering, 490 California Ave., Suite 200, Palo Alto, CA 94306.

[29] Sense8 Corporation, 100 Shoreline Hwy, Suite 282, Mill Valley, CA 94941 [(415) 331-6318, http:// www.sense8.com].

[30] H. S. Fogler, S. M. Montgomery, and R. P. Zipp, "Interactive computer modules for chemical engineering instruction,' Comput. Appl. Eng. Educ., Vol. 1, No. 1, 1992, pp. 11-24.

[31] S. M. Walas, Chemical Process Equipment, Selection and Design, Butterworths, Boston, 1988.

[32] CACHE Corporation (Computer Aids for Chemical Engineering), P.O. Box 7939, Austin, TX 78713 7939 [(512) 471-4933, cache@utxvm.cc.utexas.edu].

[33] J. T. Bell and H. S. Fogler, "Recent developments in virtual reality based education,' Proceedings of the American Society for Engineering Education Annual Conference, Washington, DC, June 1996.

[34] J. T. Bell and H. S. Fogler, "Preliminary testing of a virtual reality based module for safety and hazard evaluation,' Proceedings of the 1996 Illinois/Indiana ASEE Sectional Conference, March 1996, Bradley University, Peoria, IL.

the world. His most recent book, Strategies for Creative Problem Solving, coauthored with Steven E. LeBlanc, was published by Prentice Hall in August 1995.

In 1980, Professor Fogler was a first recipient of the newly instituted award for Outstanding Research from the University of Michigan College of Engineering. Also, he received in 1980 the Chemical Engineer of the Year Award from the Detroit section of the American Institute of Chemical Engineers. In 1984, he was appointed the Vennema Distinguished Professor of Chemical Engineering. He received the University of Colorado Distinguished Alumnus Award in 1987, and in 1988 he was elected president of the Computer Aids for Chemical Engineering (CACHE) Corporation. In 1993, he received the W. Corcoran Award for Best Paper in Chemical Engineering Education. In 1994, he was elected a director of the American Institute of Chemical Engineers and a fellow of the AIChE, and he was selected as an advisory editor for the Prentice Hall International Series in the Physical and Chemical Engineering Sciences. Also in 1994 he received the Inaugural Adler Lectureship at Case Western Reserve University and was a McCabe Lecturer at North Carolina State University. Most recently, he received in 1995 the AIChE Warren K. Lewis Award. 